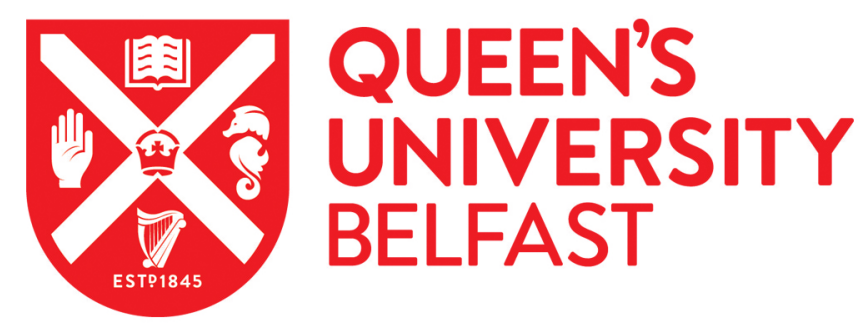

\title{
Research Protocol: A Randomized Controlled Trial of Functional Family Therapy: An Early Intervention Foundation (EIF) Partnership between Croydon Council and Queen's University Belfast
}

Thurston, A., Miller, S., Dunne, L., Lazenbatt, A., Gildea, A., Stepien, D., \& Tapsell, D. (2015). Research Protocol: A Randomized Controlled Trial of Functional Family Therapy: An Early Intervention Foundation (EIF) Partnership between Croydon Council and Queen's University Belfast. International Journal of Educational Research, 70, 47-56. https://doi.org/10.1016/j.ijer.2015.01.001

Published in:

International Journal of Educational Research

Document Version:

Early version, also known as pre-print

Queen's University Belfast - Research Portal:

Link to publication record in Queen's University Belfast Research Portal

Publisher rights

(c) 2015 the author

\section{General rights}

Copyright for the publications made accessible via the Queen's University Belfast Research Portal is retained by the author(s) and / or other copyright owners and it is a condition of accessing these publications that users recognise and abide by the legal requirements associated with these rights.

Take down policy

The Research Portal is Queen's institutional repository that provides access to Queen's research output. Every effort has been made to ensure that content in the Research Portal does not infringe any person's rights, or applicable UK laws. If you discover content in the Research Portal that you believe breaches copyright or violates any law, please contact openaccess@qub.ac.uk. 


\title{
Research Protocol: A Randomized Controlled Trial of Functional Family Therapy: An Early Intervention Foundation (EIF) Partnership between Croydon Council and Queen's University Belfast
}

\section{Authors}

Allen Thurston (Queen's University Belfast), Sarah Miller (Queen's University Belfast), Laura Dunne (Queen's University Belfast), Anne Lazenbatt (Queen's University Belfast), Aideen Gildea (Queen's University Belfast), Dwynwen Stepien (Croydon Council), Dave Tapsell (Croydon Council)

\begin{abstract}
The paper presents a protocol for 'A Randomized Controlled Trial of Functional Family Therapy (FFT): An Early Intervention Foundation (EIF) Partnership between Croydon Council and Queen's University Belfast'. The protocol describes a trial that uses FFT as an alternative intervention to current use of the youth justice system and local authority care with the aim of reducing crime/recidivism in young people referred to Croydon Council. The trial will take place over a period of 36 months and will involve up to 154 families. Croydon Council will employ a team of five Functional Family Therapists who will work with families to promote effective outcomes. The Centre for Effective Education at Queen's University Belfast will act as independent evaluators of outcomes for families and young people. The work is supported from the United Kingdom Economic \& Social Research Council/Early Intervention Foundation Grant Number ES/M006921/1.
\end{abstract}

\section{Introduction}

For some troubled and troubling adolescents care orders and/or entry to juvenile justice systems leads to reduced quality of life outcomes. This often comes at the end of a series of events where effective early intervention could have alleviated the problem (Farrington \& Welsh, 2003). These adolescents are known to live in 'high risk families'. Adolescent risk factors include family poverty and violence, child maltreatment, separations, lack of opportunities to develop secure attachments, and harsh, lax or inconsistent discipline, substance misuse and psychiatric co-morbidity such as attention-deficit hyperactivity disorder (ADHD) and conduct disorder (Fisher et al., 2002; Satterfield et al., 2007; Mordre et al., 2011). Parenting behaviour such as domestic abuse, alcohol and drug misuse and parental mental health problems such as depression are among the strongest predictors of child conduct problems (Cicchetti \& Manly, 2001). Protective factors include having parents with caregiving skills that can support development of increased competence and selfesteem; and pro-social peers and a school environment that creates success, responsibility and self-discipline. These have both been shown to be important in preventing conduct and behavioural problems (Rutter, 1979). Indeed, two principal risk factors for offending are low educational attainment and weak engagement with school (Stephenson, 2007). Young people who are exposed to cumulative risk factors and exhibit conduct disorder behaviours are more likely to leave school early and with fewer qualifications, have fewer social skills, and need more special education. It is not uncommon for parent-child interactions to be characterised by anti-social, aggressive and violent behaviour (Kazdin, 1997), leading to higher rates of domestic abuse (Mullender et al., 2009). Thus, the need for early intervention is vital as Loeber et al., (1993) demonstrate that children who become violent as adolescents can be identified with almost $50 \%$ reliability as early as age 7 , as a result of their aggressive and disruptive behaviour at home and at school. 
Working one-to-one with these troubled and troubling adolescents is often not enough. These young people are nested within family units that have a powerful controlling influence on core values and beliefs. This project describes a programme of research that would explore the process and effectiveness of early intervention with the families of troubled and troubling adolescent(s). The early intervention selected is Functional Family Therapy (FFT), which has been shown to positively impact on families with troubled and troubling adolescents in the USA. FFT includes a focus on and assessment of those risks and protective factors that impact upon the adolescent and his or her environment, with specific attention paid to both intra-familial and extra-familial factors, and how they present within and influence the therapeutic process. It is a specialist form of therapy that requires a systematic, manualised approach and specialist training (BACP, 2014). It is currently being introduced in Croydon. That gives the research team a unique opportunity to establish a randomized controlled trial (RCT) to assess the effectiveness of the intervention over treatment as usual.

\section{Previous work and background}

Counselling psychologists acknowledge that family-based therapy can prove effective at treating conditions that on the surface appear to be individualised problems e.g. substance abuse, anxiety disorders, depression, agoraphobia, conduct disorder (Alexander et al.,1993). FFT has a history of systematic research that dates back many years (Alexander \& Parsons, 1973), resulting in 13 published clinical trials, which suggest that FFT is effective in reducing recidivism between $26 \%$ and $73 \%$ with offending, moderate, and seriously delinquent youth as compared to both no treatment and juvenile court probation services (Alexander et al., 2000). In one research review it was reported that the use of FFT reduced the likelihood of offending by $27 \%$ (Sexton \& Alexander, 2002). A design experiment reported involving 54 'juvenile delinquents' (original term) from rural, lower socioeconomic backgrounds in Ohio, USA reported reduced offending due to FFT. In the study offending rates for a sample of 27 'treated' individuals were $9 \%$ as compared to a rate of $41 \%$ amongst a sample of 27 who received treatment as usual (probation) (Gordon et al.,1995). A metaanalysis of the effectiveness of family-based crime prevention programmes reviewed 40 programmes of family therapy and concluded that reduced offending rates were observed in studies with a mean Effect Size $=+0.321$. Effect Sizes were generally greater for those programmes that focused on behaviour change and were situated outside of the school setting (Farrington \& Welsh, 2003).

However, these studies all used samples from the USA, where the evaluation team played significant roles in developing and delivering FFT and/or were not randomized controlled trials (RCTs). Consequently, it is both timely and necessary to have a rigorous test of FFT's efficacy in UK populations as well as a need for this systematic evaluation to be undertaken by a team independent from those implementing FFT. The best method of undertaking this will be a RCT. This would adhere strictly to CONSORT guidelines that ensure best practice in conducting RCTs. Thus, the current proposal dovetails with the EIF 'Standards of Evidence' framework for 'What works?' This research will provide robust evidence to other teams involved in early intervention with families/troubled and troubling adolescents as to whether FFT offers a valid, effective and efficient means of providing early intervention. Currently the FFT intervention offers effective intervention with EIF Level 4 standard of evidence. This study will enable the programme to be assessed in the new context (Croydon) and therefore enable EIF to determine whether FFT would be worthy of a Level 5 rating (EIF, 2014a).

FFT is a strengths-based behavioural family intervention involving approximately 12 
sessions, which take between three and six months to complete. It aims to replace destructive and maladaptive interaction patterns with increased reciprocity of communication and more adaptive functioning within the family (Alexander \& Parsons, 1973). It is a manualised intervention that can be home, office or community-based and is delivered by therapists specifically trained in the programme's delivery. The therapy originally evolved from family interaction studies conducted in the sixties and seventies, which reported that dysfunctional families were more likely to lack reciprocity in their interactions (Patterson \& Reid 1970). Such families tended to be more silent, talk less equally, have fewer positive interruptions and be less active (Alexander, 1970; Duncan, 1968; Mischler \& Waxler, 1968; Stuart, 1968; Winter \& Ferreira, 1969). Within this framework juvenile delinquent behaviour is viewed as a function of the maladaptive system in which the young person is embedded (i.e. the family), which in turn results in the young person being more susceptible to the negative influence of their peer group thereby increasing their risk of reoffending (Sexton \& Turner, 2010). The programme developers describe the therapy as being family focused and non-judgemental, based on respect for difference and with an emphasis on the risk and particularly the protective factors that impact upon the young person. It adopts a tailored approach specific to the presenting issues of the family and young person and is relational in nature rather than focused on any one individual's problems (e.g. Alexander \& Parsons, 1973, 1982; Kazdin, 1997; Sexton \& Turner, 2010, Alexander, Waldron, Robbins \& Neeb, 2013). Throughout the duration of the programme therapists model and encourage clear communication of feelings, clear expression of demands and alternative solutions, all of which are designed to lead to family members negotiating with each other and ultimately achieving compromise (Alexander \& Parsons, 1973).

There are three main stages to FFT: engagement, behaviour change, and generalisation (Sexton, 2011). Firstly, treatment aims to engage and motivate families and young people; acknowledging the context in which a family finds itself and increasing the communication and positive reinforcement between family members as well as decreasing negativity, such as blaming or hopelessness. It also aims to reduce and extinguish problem behaviour patterns by utilising tailored interventions and drawing on behavioural, cognitive and social learning techniques that will provide family members with problem solving and conflict management skills. Finally, the programme aims to equip the family to generalise what they have learned to other problem situations thereby enabling the family to utilise the resources they have access to as well as the skills they have learned to prevent relapse.

\section{Aims \& Objectives}

This proposal aims to establish a partnership between the Early Intervention Foundation Centre in Croydon and Queen's University Belfast through a three-year project to research the impact of FFT on outcomes related to juvenile offending, entering care for young people due to family breakdown, school attendance and family functioning is desribed. The project is split into three phases. Phase 1 is a Pilot and preparation for main study. Phase 2 aims to conduct an RCT of FFT in up to 154 families. Phase 3 is an analysis, impact and knowledge exchange phase. The overall objectives of the project are to:

- Establish FFT for troubled and troublesome families working as part of the Croydon Early Intervention Foundation Centre.

- Evaluate the effectiveness of FFT on reducing juvenile offending/entering care for young people due to family breakdown and improving school attendance/family functioning through a RCT of FFT.

- Use results of planned evaluation to enhance future implementation of FFT beyond the 
life of the proposed research project.

- Examine the economics surrounding this approach of FFT and model the proposed costbenefit of wider role out of FFT in Croydon.

\section{Research questions}

- What is the effect of FFT on probability of offending of juveniles in 'at risk' families?

- What is the effect of FFT on probability of entering care for young people in 'at risk' families due to family breakdown?

- What is the effect of FFT on school/college attendance of juveniles in 'at risk' families?

- What are the effects of FFT on reported family functioning?

- What are the potential costs or savings of using FFT as opposed to existing practice in Croydon?

\section{Methodology}

The project will run in three phases:

- Phase 1: Pilot and preparation for main study

- Phase 2: Main study randomized controlled trial

- Phase 3: Analysis, impact and knowledge exchange

These phases are described in detail below.

\section{Phase 1: Pilot and preparation for main study (12 months duration)}

Phase 1 of the project would establish methodologies and measures that will be used in the main randomized trial. There will be a need to pilot instruments and measures with families and therapists (up to 50 intervention families, 5 therapists). During this phase Croydon will establish training for therapists in FFT and establish FFT as an intervention. This is a new venture in Croydon. This phase will be important so that therapists become skilled in using FFT with families and are familiar with the objectives of the trial and their role within this, including the purpose and process of randomisation. The outcomes of Phase 1 would be:

- The delivery of FFT is established in Croydon.

- Criteria are established for inclusion/exclusion of families in the study.

- Process of randomization for main study will be developed and tested. All families referred to the Family Resilience Service (FRS) through the 'early help' initiative will be assessed using inclusion/exclusion criteria. Those meeting inclusion criteria will be randomized using a pre-defined template (using criteria most likely to describe variance in outcomes such as gender, race and prior offending behavior to create 'blockrandomized' groups). This is likely to be done using a flow diagram to assign families referred to FRS with similar criteria to intervention (FFT) and control (treatment as usual) groups alternately.

- Measures piloted and their efficacy established.

- Methods of data collection are established and tested and proven to be robust: This will involve the establishment of effective working partnerships with Croydon staff who will be sub-contracted to Queen's University Belfast. In addition there will be a requirement to establish and test secure methods of data transfer using encryption software.

- Methodologies instruments and measures will have been tested and enhanced. This will include interview templates, instruments of family functioning and pulling data out from Croydon data management systems about targeted 'at risk' families.

- At the end of Phase 1 there will have been establishment of factors that predicted 
'intention to treat ${ }^{1}$ for families that have resulted in 'full treatment ${ }^{1}$ (i.e. what was the profile of a family likely to stay in treatment). This will involve collecting background ethnographic data on families which will include family composition, age of children and siblings, special educational needs of children, parental mental health, free-school meal status of children, school attended. These factors will be modelled to see how they correlate to completion of intended treatment sessions and then the predictive factors that emerge used to randomize the sample in Phase 2. This will be important because the most likely influence on outcomes in the intention to treat group should be 'dose' received.

\section{Phase 2: Main study randomized controlled trial (12 months duration)}

Phase 2 will undertake a RCT to establish the impact of FFT (with up to 154 families) during a six-month treatment period. Croydon see approximately 250 families per year who meet the threshold for closer supervision. Predictive factors of 'completion of therapy' will be used to determine which families will be eligible to take part in the trial. The unit of randomization will be the family, thus eligible families will be randomly allocated to receive either FFT (the intervention group) or to receive 'treatment as usual' (the control group). This will happen continuously as families present to Croydon Family Resilience service. A logic diagram will be used to sort referrals into groups based on descriptors. A random number generator will be used to generate the start 'condition' for each list. Then families on the list will be allocated to condition turn-wise to ensure even numbers are allocated to each condition i.e. if the first family in the list of white, male, no previous offending presentation is allocated to control, the next family is allocated to experimental, the next to control and so forth. The sample size (77) should allow for full treatment for selected families within Phase 2. If FFT is shown to be effective on the main outcome measures then it will be offered to the treatment as usual group on completion of the trial if appropriate. CONSORT guidelines will be followed as far as possible and this includes the provision for the analysis to be conducted blind to condition (undertaken by Miller).

Primary outcomes to be tested for would be:

- Probability of reduction of offending of FFT

- Probability of reduction of entering for young people due to family breakdown of FFT

Secondary outcome measures will be:

- Effects on family functioning of FFT: the instrument used for this section of the study will be the SDQ Questionnaire, which is a 25, item instrument scored on a three-point Likert scale. In a sample of 10,438, British 5-15 year-old children internal consistency on the three sub-scales was good with mean reported Cronbach alpha values of 0.73 (Goodman, 2001).

- Effects on school/college attendance of FFT

- Critical analysis of effective components of FFT (obtained through exit/change interviews with families who have been involved in FFT)

At the end of phase 2 there will be some initial analysis of quantitative data, which will be made available to the FFT team at Croydon via a preliminary report.

\section{Phase 3: Analysis, impact and knowledge exchange (12 months duration)}

One of the exciting things about this proposal is that the research phase has the potential to directly inform the practice of the FFT team in Croydon. This offers exciting possibilities of using research data directly during an analysis, impact and knowledge exchange phase of the project. During Phase 3 a final report that analyses the main outcome measures and triangulates them with qualitative and process data will be produced. This will go beyond the 
reports normally drafted as part of the ESRC final report requirements. It will form the basis of a knowledge exchange conversation between the implementation and evaluation teams. This should enable the effectiveness of the FFT model to be fine tuned on the basis of evidence to meet the specific local needs and requirements of Croydon. This would help Croydon move FFT from Level 3 in the EIF Maturity Matrix Self-assessment Tool (Substantial Progress) to Level 4 (Maturity) where the strategy changes on the ground (EIF, 2014b). Treatment for any of the families assigned to the delayed treatment group, whom have not already been treated after the delay time, will also be undertaken (about 12-months after allocation to condition). Finally follow-up measures will be collected on families from intervention and treatment as usual conditions at this 12-month point to assess the longer term impact of FFT.

\section{Instruments and measures}

The range of data collected and the instruments used to collect these is presented in Table 1.

Table 1: Instruments and measures (collected at this point $=\boldsymbol{V}$; not collected at this point $=\mathrm{x}$ )

\begin{tabular}{|c|c|c|c|c|}
\hline Measure & $\begin{array}{l}\text { Pre-test: } \\
\text { start of } \\
\text { intervention }\end{array}$ & $\begin{array}{l}\text { Post-test: } \\
\text { after } 6 \\
\text { months }\end{array}$ & $\begin{array}{l}\text { Follow- } \\
\text { up: after } \\
12 \text { months }\end{array}$ & Method of data collection \\
\hline $\begin{array}{l}\text { Probability of offending-impact on } \\
\text { young people }\end{array}$ & $x$ & $\checkmark$ & $\checkmark$ & $\begin{array}{l}\text { Collected by staff at Croydon } \\
\text { from Croydon existing data } \\
\text { bases 6-months after the start } \\
\text { of allocation to condition }\end{array}$ \\
\hline $\begin{array}{l}\text { Probability of reduction of entering } \\
\text { care for young people due to family } \\
\text { breakdown of FFT }\end{array}$ & $x$ & $\checkmark$ & $\checkmark$ & $\begin{array}{l}\text { Collected by staff at Croydon } \\
\text { from Croydon existing data } \\
\text { bases 6/12-months after the } \\
\text { start of intervention }\end{array}$ \\
\hline $\begin{array}{l}\text { Attendance at school-impact on } \\
\text { young people }\end{array}$ & $x$ & $\checkmark$ & $\checkmark$ & $\begin{array}{l}\text { Collected by research assistant } \\
\text { from Queen's University Belfast } \\
\text { (QUB) from schools in Croydon }\end{array}$ \\
\hline $\begin{array}{l}\text { Exit/change interviews with } \\
\text { families-30 families from the } \\
\text { treatment condition will be } \\
\text { interviewed using 'change' interview } \\
\text { techniques (Thurston et al 2012).- } \\
\text { impact on family including parents } \\
\text { and siblings }\end{array}$ & $x$ & $\checkmark$ & $x$ & $\begin{array}{l}\text { Collected by research assistant } \\
\text { from Queen's University Belfast } \\
\text { (QUB) during final family } \\
\text { therapy session }\end{array}$ \\
\hline $\begin{array}{l}\text { Measure of family functioning SDQ- } \\
\text { impact on family including parents } \\
\text { and siblings }\end{array}$ & $\checkmark$ & $\checkmark$ & $x$ & $\begin{array}{l}\text { Collected by therapist during } \\
\text { therapy session }\end{array}$ \\
\hline $\begin{array}{l}\text { Ethnographic data on families - This } \\
\text { will be collected at entry to the } \\
\text { system along with ethical consent } \\
\text { for sharing of data. }\end{array}$ & $\checkmark$ & $x$ & $x$ & $\begin{array}{l}\text { Collected by staff at Croydon } \\
\text { from Croydon existing data } \\
\text { bases prior to the start of } \\
\text { allocation to condition }\end{array}$ \\
\hline $\begin{array}{l}\text { Treatment records from } \\
\text { Counsellors - the frequency, } \\
\text { duration and attendance of client } \\
\text { families in the intervention group } \\
\text { and impact on family including } \\
\text { parents and siblings will be } \\
\text { collected. }\end{array}$ & $x$ & $\checkmark$ & $x$ & $\begin{array}{l}\text { Collected by therapist during } \\
\text { therapy session }\end{array}$ \\
\hline
\end{tabular}


The core characteristics (gender, education level, age, deprivation) of the intervention and treatment as usual groups will be described and compared at baseline. At the end of the RCT the effects of the intervention will be estimated using a series of multivariate regression models for each outcome measure. For each model the post test score will form the dependent variable and a number of independent variables will be added, including: a dummy variable representing group allocation (where 1=intervention group and $0=$ treatment as usual group) and other covariates representing core characteristics and pretest scores on relevant outcome measures. The main outcome analysis will use logistic regression to estimate the relative risk of (re)offending and entering care for young people due to family breakdown for those in the intervention and treatment as usual groups. Linear regression will be used to determine the impact of the intervention on continuous outcomes. The estimated coefficient associated with the dummy variable that represents 'group allocation' (once other covariates have been controlled for) will be the focus of the analysis in terms of its value in the model as a significant predictor of the outcome.

Calculations to determine sample size have been undertaken using Optimal Design V 3.01 software (Raudenbuch et al., 2011). The regression has been modeled with:

\author{
Alpha $=0.05$ \\ Power $=80 \%$ \\ Proportion of explained variation by level 1 covariates $\left(R^{2}\right)=0.7$
}

For a minimum detectable Effect Size (ES) of +0.32 Optimal Design calculates that we will need a total sample size of $N=95$. This will give 48 in FFT and 48 in treatment as usual. We also modeled for a minimum detectable lower ES of +0.25 and would need a total sample size of $N=154$ i.e. 77 in FFT and 77 in treatment as usual. It should also be noted that if $\mathrm{R}^{2}=0.5$ on level 1 covariates, then we could detect an ES of 0.32 with a sample of 154 . As was stated in the interview the project should have access to nearly 250 families who will be referred to the team at the EIF Centre in Croydon. Given the extent of the infrastructure at Croydon the team will be able to offer FFT to 100 of these families in the first year of operations after the pilot phase (leaving 100 families to receive treatment as usual). Therefore, we believe that the sample of 95 families is achievable (requiring just under half of the potential families to participate). If initial data collected during the pilot phase indicated that the reported ES would not be realised, or our assumptions of the strength of level 1 covariates of $\mathrm{R}^{2}$ prove to be overestimated, then we would reserve the option to recruit up to 154 into the study to cater for the possibility that smaller ES of +0.25 , or indeed a level 1 covariate $R^{2}=0.5$, to enable us to retain the correct power in subsequent analysis. We feel that we would be able to collect data on primary outcomes for this larger estimated sample (and those secondary outcomes of a quantitative nature, requiring the same power for subsequent analysis). However, the estimate of ES is based on aggregated studies during our initial literature search. We noted that targeted interventions tended to yield larger ES. The Croydon intervention is targeted and therefore we would not anticipate issues in relation to not achieving the 'historical' ES reported in previous literature. We are aware that different software would calculate sample size differently (eg freeware available from Daniel Soper, California State University). However, we have taken the more conservative figure given by Optimal Design as our definitive figure. Optimal Design is software from University of Michigan and is widely accepted as a reliable and precise source from which to calculate sample sizes. By taking this more conservative estimate of sample size we again hope to proof the study design against future issues relating to under-power of regression analyses.

The graph of sample size plotted with ES for our model produced by Optimal Design is illustrated in Figure $1 \mathrm{a}$ for $\mathrm{R}^{2}=0.7$ and the way in which sample size prediction is affected by 
a lower $R^{2}$ value $\left(R^{2}=0.5\right)$ is illustrated in Figure 2 . As can be seen a lower level 1 covariate $\mathrm{R}^{2}$ value would require a larger sample size to maintain adequate power in post-project statistical analyses.

Figure 1: Optimal Design sample size plotted with Effect Size for our model for $\mathrm{R}^{2}=0.7$

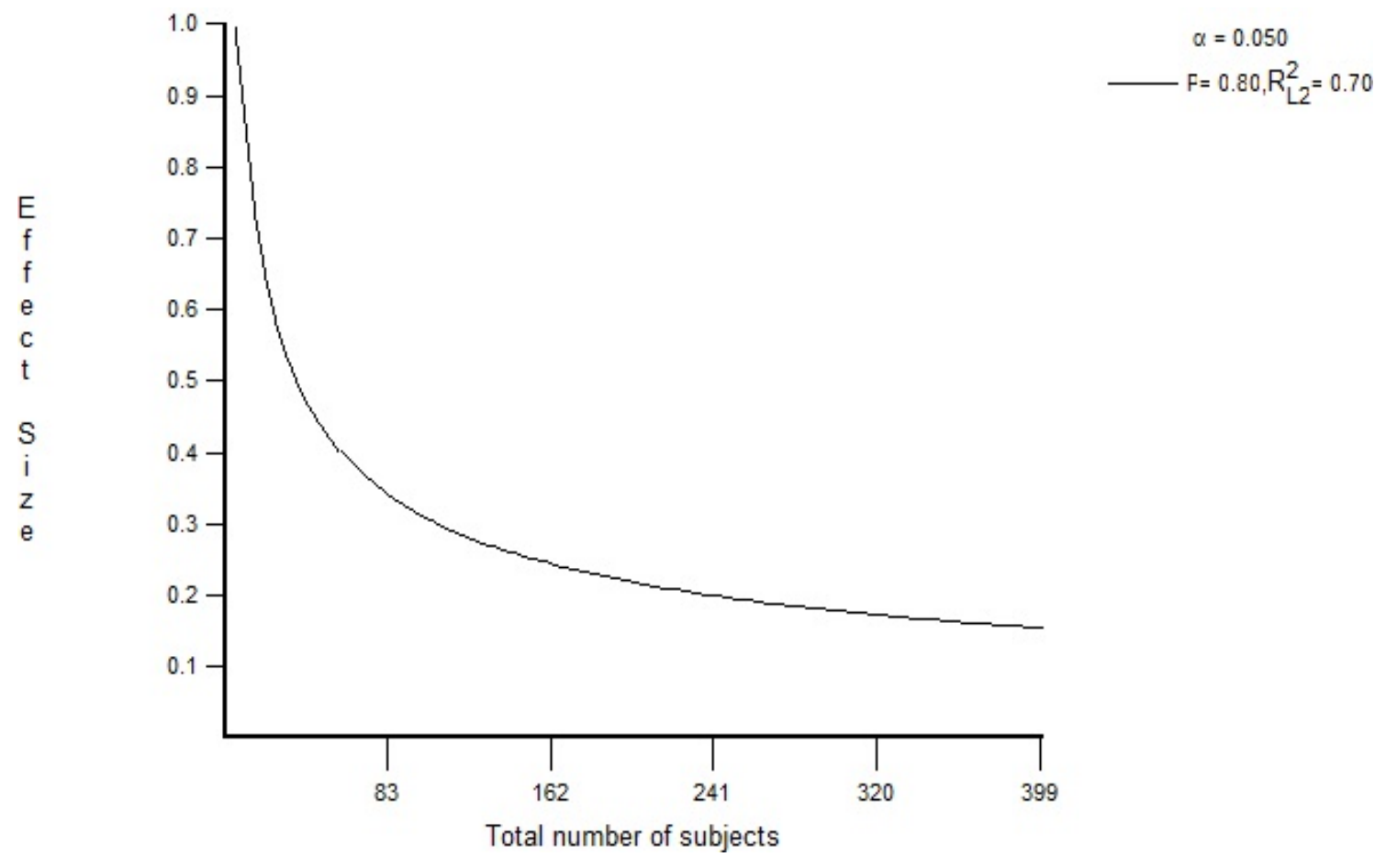

Figure 2: Optimal Design sample size plotted with Effect Size for our model for $\mathrm{R}^{2}=0.5$ \& $\mathrm{R}^{2}=0.7$

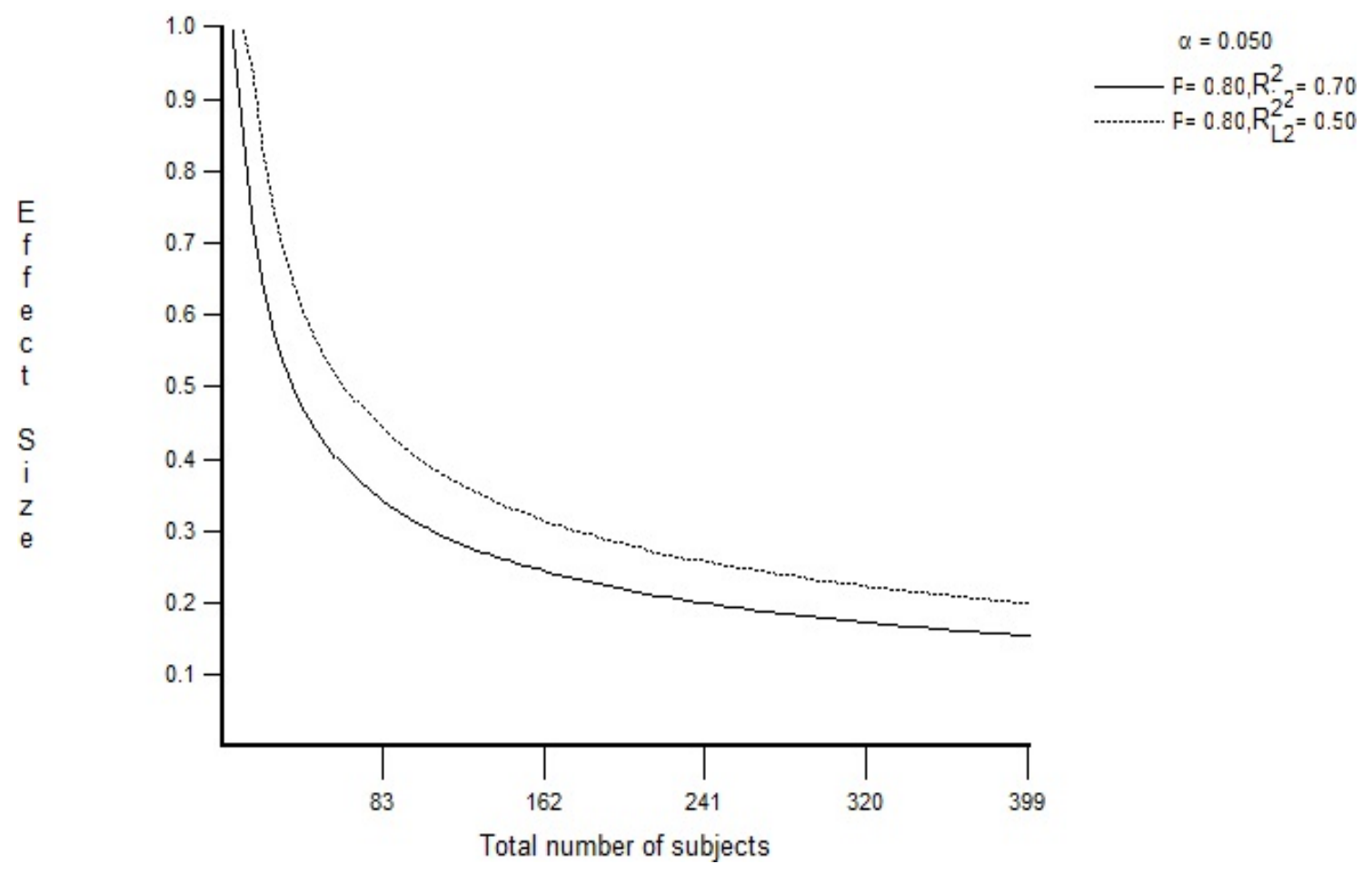

Initial thinking is that the level 1 covariates used in the model are likely to be gender and prior offending behaviours (with a possibility of ethnicity also being included). Literature 
supports a hypothesis that these factors are likely to explain substantive amounts of variance in the sample. It was reported that in a UK sample of 22,205 youth offenders aged 10-17 years-old that $67 \%$ of youth offenders were male (of these $64 \%$ were recorded as white and 14\% were recorded as black) and of the 33\% female youth offenders $72 \%$ were White and 13\% black (Youth Justice Board for England and Wales, 2010; p50). In a study of FFT involving 917 families in 14 counties in the USA gender (being male) and prior offending behaviours were reported to be the most significant predictors of post-FFT offending (Sexton \& Turner, 2010). In the UK there are reports that in some areas, particularly those with higher than national average black and minority ethnic youths, ethnicity can predict appearance in the youth custody system (Youth Justice Board for England and Wales, 2010; p18, p40). Therefore, there could be confidence that if gender, ethnicity and prior offending behaviours were selected as covariates then the variation in the model explained by these could be reasonably estimated at 0.7 . However, the study has a pilot phase, and although the model would be finalised before the start of the randomized controlled trial, there would be a chance to consider the covariates used in the model to ensure the correct covariates are chosen to obtain maximal efficiency in the model. In respect of this, analysis will also examine the likely contribution of diagnosis of conduct disorders and the pre-test SDQ measure as detailed in our proposal to see if they would be better covariates. Therefore, the estimate of $\mathrm{R}^{2}$ is not likely to be overly optimistic, but there is a contingency to select different level 1 covariates if the pilot reveals that outcomes would be better explained by using a different set of covariates.

\section{Missing data}

Analysis will run 'intention to treat' models. For families who have dropped out of the randomized controlled trial will be contacted to request participation in post-tests. Data on the primary outcome measures should be possible through administrative data sets (Liquid Locic is the data management system being developed by Croydon). However, the study is draw from a vulnerable population and there is a possibility that they may 'disappear' making such analysis virtually impossible. Therefore, the plan to deal with missing data will be as follows.

In relation to how missing data will be treated:

1. A complete case analysis will first be conducted.

2. The extent of missing data will be reported i.e. the proportion of missing data, the pattern of missing data and the reasons for missing data (with a particular emphasis on variables which might be predictive of missing data) to determine whether missing data are likely to be missing completely at random (MCAR), missing at random (MAR) or missing not at random (MNAR).

3. If more than $5 \%$ of data are missing, multiple imputation methods will be employed.

4. Sensitivity analysis will be conducted to compare the conclusions obtained for a range of different behaviours for the missing observations.

There are insufficient clusters $(n<30)$ to allow for HLM analyses to be undertaken determining effects of clustering at the Counsellor level. A cluster RCT approach to undertaking this work would not be possible within the confines of the funding model.

\section{Cost effectiveness}

Final analysis will include a cost-effectiveness model for cost of service/reduction of offending/entering care for young people due to family breakdown and will calculate the 
incremental cost effectiveness ratio (ICER) which will give an indication (if FFT is shown to be effective) of how much the observed effect costs to achieve, relative to the cost (and effect) of delivering the treatment as usual condition. It should be noted that treatment as usual currently includes a number of solutions including entering juvenile justice system, being placed under local authority care and receiving statutory visits from social work. This may include the Youth Offending Service (YOS) and Family Resilience Service at Croydon (FRS). Given that the prospective costs of these two outcomes to Croydon are relatively well understood, then by calculating the cost of FFT (currently estimated at $£ 3,000 /$ family) and comparing it to existing services such as FRS and YOS (current estimates between $£ 20,000-£ 60,000 /$ family dependent upon intervention provided) then the cost per impact unit can be established. These estimated figures will be explored in finer detail before such analysis is undertaken. This will lead to economic modeling of the cost effectiveness of FFT in Croydon. In addition the profile of families at risk of not finishing treatment should be understood and an action plan put in place to monitor such families and provide addition support to lessen that risk.

\section{Workplan and Timeline}

The workplan and timeline for the protocol is presented in Table 2.

Table 2: Workplan and timeline for the protocol

\begin{tabular}{|c|c|c|}
\hline Task & $\begin{array}{l}\text { Date/ } \\
\text { deadline }\end{array}$ & Responsibility \\
\hline Recruit RA & Dec 14 & $\begin{array}{l}\text { Allen Thurston, } \\
\text { Laura Dunne } \\
\text { (both QUB) }\end{array}$ \\
\hline FFT is established in Croydon & $\begin{array}{l}\text { To start in } \\
\text { Oct } 14 \text { and } \\
\text { be fully } \\
\text { functional } \\
\text { by Jun } 15\end{array}$ & $\begin{array}{l}\text { Dwynwen } \\
\text { Stepien, Head of } \\
\text { Early Intervention } \\
\text { Support Service, } \\
\text { Croydon Council }\end{array}$ \\
\hline $\begin{array}{l}\text { Inclusion/exclusion to study criteria for families will be } \\
\text { established with Croydon }\end{array}$ & Oct 14 & $\begin{array}{l}\text { Allen Thurston, } \\
\text { Sarah Miller } \\
\text { (QUB) \& } \\
\text { Dwynwen Stepien } \\
\text { (Croydon) }\end{array}$ \\
\hline Measures piloted and their efficacy established & $\begin{array}{l}\text { Starting in } \\
\text { Oct } 14 \text { and } \\
\text { ending in } \\
\text { Jun } 15\end{array}$ & $\begin{array}{l}\text { Allen Thurston, } \\
\text { Laura Dunne, } \\
\text { Sarah Miller } \\
\text { (QUB), RA (QUB } \\
\text { to be appointed) }\end{array}$ \\
\hline $\begin{array}{l}\text { Methods of data collection are established and tested and } \\
\text { proven to be robust: This will involve the establishment of } \\
\text { effective working partnerships with Croydon staff who will be } \\
\text { sub-contracted to Queen's University Belfast. In addition there } \\
\text { will be a requirement to establish and test secure methods of } \\
\text { data transfer using encryption software. }\end{array}$ & $\begin{array}{l}\text { Starting in } \\
\text { Oct } 14 \text { and } \\
\text { ending in } \\
\text { Jun } 15\end{array}$ & $\begin{array}{l}\text { Allen Thurston, } \\
\text { Laura Dunne, } \\
\text { Sarah Miller, RA } \\
\text { (to be appointed), } \\
\text { Jonathan Driscoll } \\
\text { \& Sarah Worboys } \\
\text { (both Croydon) }\end{array}$ \\
\hline $\begin{array}{l}\text { Methodologies instruments and measures will have been } \\
\text { tested and enhanced. This will include interview templates, } \\
\text { instruments of family functioning and pulling data out from } \\
\text { Croydon data management systems about targeted 'at risk' } \\
\text { families. }\end{array}$ & Jun 15 & $\begin{array}{l}\text { Allen Thurston, } \\
\text { Laura Dunne, } \\
\text { Sarah Miller, RA } \\
\text { (to be appointed), } \\
\text { Jonathan Driscoll } \\
\text { \& Sarah Worboys }\end{array}$ \\
\hline
\end{tabular}




\begin{tabular}{|c|c|c|}
\hline & & (both Croydon) \\
\hline $\begin{array}{l}\text { At the end of Phase } 1 \text { (as detailed in the Case for Support) } \\
\text { there will have been establishment of factors that predicted } \\
\text { 'intention to treat }{ }^{1} \text { for families that have resulted in 'full } \\
\text { treatment }^{1} \text { (i.e. what was the profile of a family likely to stay in } \\
\text { treatment). }\end{array}$ & Jun 15 & $\begin{array}{l}\text { Allen Thurston \& } \\
\text { Sarah Miller }\end{array}$ \\
\hline $\begin{array}{l}\text { Recruit to main trial and randomise to condition (note that this } \\
\text { time period can be extended if required, but this scenario is } \\
\text { considered very unlikely) }\end{array}$ & $\begin{array}{l}\text { Oct } 15-\text { Oct } \\
16 \text { as } \\
\text { families are } \\
\text { recruited to } \\
\text { the study }\end{array}$ & $\begin{array}{l}\text { Allen Thurston \& } \\
\text { Sarah Miller }\end{array}$ \\
\hline Collect demographic data on families & $\begin{array}{l}\text { Oct 15-Oct } \\
16\end{array}$ & $\begin{array}{l}\text { Laura Dunne, RA, } \\
\text { Jonathan Driscoll } \\
\text { \& Sarah Worboys }\end{array}$ \\
\hline $\begin{array}{l}\text { Collect data on outcomes for families at } 6 / 12 \text { months as } \\
\text { indicated in Case for Support including: } \\
\text { 1) Probability of reduction of offending of FFT ( } 6 / 12 \text { months) } \\
\text { 2) Probability of reduction of entering care for young people } \\
\text { due to family breakdown FFT } \\
\text { 3) Measure of Family Functioning SDQ ( } 6 / 12 \text { months) } \\
\text { 4) Effects on school/college attendance of FFT(6/12 months) } \\
\text { 5) Critical analysis of effective components of FFT (obtained } \\
\text { through exit/change interviews with families who have } \\
\text { been involved in FFT) ( } 6 \text { months) }\end{array}$ & $\begin{array}{l}\text { Oct } 15-\text {-Oct } \\
17\end{array}$ & $\begin{array}{l}\text { 1, 2, 3) Laura } \\
\text { Dunne, RA, } \\
\text { Jonathan Driscoll } \\
\text { \& Sarah Worboys } \\
\text { 4) Laura Dunne, } \\
\text { RA } \\
\text { 5) Laura Dunne, } \\
\text { RA }\end{array}$ \\
\hline $\begin{array}{l}\text { Data analysis on outcomes including: } \\
\text { 1) Probability analysis on offending and entering care for } \\
\text { young people due to family breakdown at } 6 \text { and } 12 \text { month } \\
\text { time periods } \\
\text { 2) Family functioning outcomes (incorporating treatment } \\
\text { records from therapists) at } 6 \text { months }\end{array}$ & $\begin{array}{l}\text { Oct 16-Jun } \\
17\end{array}$ & $\begin{array}{l}\text { 1) Allen Thurston, } \\
\text { Sarah Miller, RA, } \\
\text { Jonathan Driscoll } \\
\text { \& Sarah Worboys } \\
\text { 2) Allen Thurston, } \\
\text { Laura Dunne, RA, } \\
\text { Jonathan Driscoll } \\
\text { \& Sarah Worboys }\end{array}$ \\
\hline Delayed treatment control group received treatment & $\begin{array}{l}\text { Oct 16- Aug } \\
17\end{array}$ & Dwynwen Stepien \\
\hline $\begin{array}{l}\text { Impact activities undertaken as highlighted in 'Pathways to } \\
\text { Impact' document including: } \\
\text { a. Participating families will be provided with project } \\
\text { findings. } \\
\text { b. Launch event at Croydon: This will be held at a time } \\
\text { and date whereby practitioners could attend and will } \\
\text { be publicised and accompanied by a press release. } \\
\text { The CEE is a collaborator in the Science Media } \\
\text { Centre who will advise on the strategy for capturing } \\
\text { press interest. } \\
\text { c. Peer reviewed publications: Staff in CEE have a } \\
\text { strong track record in publishing work in refereed } \\
\text { academic journals. This gives work credibility. Work } \\
\text { will be published in targeted international academic } \\
\text { journals. } \\
\text { d. Conference presentations: Prior to publication in } \\
\text { journals project staff will present data at international } \\
\text { conferences. This will publicise results of the } \\
\text { research. } \\
\text { e. Presentations to Trusts } \\
\text { f. Presentations to regional School Principal meetings } \\
\text { in both Croydon and Northern Ireland }\end{array}$ & $\begin{array}{l}\text { Jun } 17- \\
\text { Aug } 18\end{array}$ & $\begin{array}{l}\text { a/b/e/f/g Allen } \\
\text { Thurston, Sarah } \\
\text { Miller, Laura } \\
\text { Dunne, RA, } \\
\text { Jonathan Driscoll, } \\
\text { Sarah Worboys \& } \\
\text { Dwynwen Stepien } \\
\text { c/d/h/i. Allen } \\
\text { Thurston, Sarah } \\
\text { Miller, Laura } \\
\text { Dunne, RA }\end{array}$ \\
\hline
\end{tabular}




\begin{tabular}{|l|l|l|}
\hline g. $\begin{array}{l}\text { Presentations to politicians throughout the UK if } \\
\text { findings present a positive prognosis of FFT. }\end{array}$ & \\
h. $\begin{array}{l}\text { Newsletters to schools: Centre for Effective } \\
\text { Education Newsletter drop to schools in the UK } \\
\text { (CEE uses Campaign Manager to disseminate } \\
\text { materials in this way) }\end{array}$ & \\
i. Social Media: Centre for Effective Education Twitter \\
$\begin{array}{l}\text { and Facebook newsfeeds would be used to } \\
\text { publicise results (currently these have about 700 } \\
\text { followers). In addition, the final report will be made } \\
\text { available via the CEE website. }\end{array}$ & & \\
\hline $\begin{array}{l}\text { Draft report written and made available to Croydon for } \\
\text { comment }\end{array}$ & $\begin{array}{l}\text { Jun 17 - } \\
\text { mid July 17 }\end{array}$ & \\
\hline Final report written and submitted to ESRC & $\begin{array}{l}\text { Mid July 17 } \\
\text { to end Aug } \\
17\end{array}$ & $\begin{array}{l}\text { Allen Thurston } \\
\text { then Sarah Miller, } \\
\text { Laura Dunne, RA, } \\
\text { Jonathan Driscoll, } \\
\text { Sarah Worboys \& } \\
\text { Dwynwen Stepien }\end{array}$ \\
\hline
\end{tabular}

\section{Ethics}

The research will adhere to ESRC ethical guidelines as well as QUB guidelines on governance and ethical research. The project will be scrutinised by the appropriate ethical committee. The project will also adhere to the AERA guidelines on ethics, the professional body of the PI and a body within which he is an office-bearer. Data handling, storage and security, will be ensured to meet acceptable ethical standards. Both the young person and their parents will be assured that what is communicated in the course of research will remain confidential to the research team, unless abuse/significant harm is disclosed, in which case the research team will follow our NSPCC protocol for informing the relevant professionals. All young people, parents and therapists will be provided with written information about the study prior to the RCT. Participation in the study is by voluntary informed consent, obtained by the researcher prior to all stages of data collection, allowing an opportunity for the young person, parents and therapists to ask questions. A copy of the consent form will be given to the young person, parent, and therapist to keep, and copies retained by the researcher. It must be stressed that all participation is voluntary and all young people, parents and professionals may withdraw from the study at anytime and for any reason. All withdrawals will be documented and the reasons, if given, recorded. Study documentation will be completed up to the point of withdrawal.

\section{References}

Alexander, J. F. (1970). A systems approach to family interaction. Paper presented at the meeting of the Rocky Mountain Psychological Association: Salt Lake City: Utah, USA..

Alexander, J. F., Holtzworth-Munroe, A., \& Jameson, P. B. (1993). Research on the process and outcome of marriage and family therapy. In A. E. Bergin \& S. L. Garfield (Eds.), Handbook of psychotherapy and behavior change (4th ed., pp. 595-630). New York: John Wiley.

Alexander, J. F., \& Parsons, B. V. (1973). Short term behavior interventions with delinquent families: Impact on family process and recidivism. Journal of Abnormal Psychology, 81, pp219- 225. 
Alexander, J. F., \& Parsons, B. V. (1982). Functional family therapy: Principles and procedures. Carmel, CA: Brooks/Cole.

Alexander, J. F., Pugh, C., Parsons, B., \& Sexton, T. L. (2000). Functional family therapy. In D. Elliott (Series Ed.), Book three: Blueprints for violence prevention (2nd ed.). Golden, CO: Venture.

Alexander J. F., Waldron, H.B., Robbins, M.S., \& Neeb, A. (2013). Functional family therapy for behavior problem adolescents. NY: American Psychological Association.

BACP (2014). Explanation of theoretical approaches: Family therapy. Retrieved from www.bacp.co.uk/seeking therapist/theoretical approaches.php

Cicchetti, D., \& Manly, J. T. (2001). Operationalizing child maltreatment: Developmental processes and outcomes. Developmental Psychopathology, 13, 755-757.

Duncan, P. (1968). Family interaction in parents of neurotic and social delinquent girls. Unpublished doctoral dissertation: University of Wisconsin.

EIF (2014a). The early Intervention Guidebook: What is it? Retrieved from www.eif.org.uk/wp-content/uploads/2014/03/Introduction-to-the-Guidebook-Final-

Slides.pdf

EIF (2014b). Early Intervention Maturity Matrix: Self-assessment Tool. Retrieved from www.eif.org.uk/wp-content/uploads/2014/03/Maturity-matrix-Feb14.pdf

Farrington, D. P., \& Welsh, B.C.(2003). Family-based prevention of offending: A metaanalysis. Australian \& New Zealand Journal of Criminology, 36, 2, pp127-151. DOI: 10.1375/acri.36.2.127

Fischer M, Barkley RA, Smallish L, Fletcher K. (2002) Young adult follow-up of hyperactive children: self-reported psychiatric disorders, comorbidity, and the role of childhood conduct problems and teen CD. J Abnormal Child Psychology 30:463-475.

Goodman, R. (2001). Psychometric properties of the Strengths and Difficulties Questionnaire (SDQ). Journal of the American Academy of Child and Adolescent Psychiatry, 40, pp1337-1345.

Gordon, D. A., Graves, K., \& Arbuthnot, J. (1995). The effect of Functional Family Therapy for delinquents on adult criminal behavior. Criminal Justice and Behavior, 22, 1, pp60-73. DOI: $10.1177 / 0093854895022001005$

Kazdin, A.E. (1997) Practitioner review: psychosocial treatments for cinduct disorder in children. Journal of Child Psychology and Psychiatry, 38(2), pp161-178.

Mischler, E., \& Waxler, N. (1968). Interaction in families. New York: Wiley.

Patterson, G. R., \& Reid, J. B. (1970). Reciprocity and coercion: Two facets of social systems. In C. Neuringer \& J. Michael (Eds.), Behavior modification in clinical psychology. New York: Appleton- Century-Crofts.

Mordre, M. Groholt, B. Kjelsberg, E. Sandstad, B. and Myhre, AM. (2011) The impact of ADHD and conduct disorder in childhood on adult delinquency: A 30 years follow-up study using official crime records BMC Psychiatry, 11:57. 
Raudenbush, S. W., et al. (2011). Optimal Design Software for Multi-level and Longitudinal Research (Version 3.01) [Software]. Available from www.wtgrantfoundation.org.

Satterfield JH, Faller KJ, Crinella FM, Schell AM, Swanson JM, Homer LD. (2007) A 30-year prospective follow-up study of hyperactive boys with conduct problems: adult criminality. J American Academy Child Adolescent Psychiatry, 46:601-610.

Sexton, T. L., (2010). Functional Family Therapy in Clinical Practice. Routledge: NY.

Sexton, T. L., \& Alexander, J.F. (2002). Family-Based Empirically Supported Interventions. The Counseling Psychologist, 30, pp238-261. DOI: 10.1177/0011000002302003

Sexton, T. L., \& Turner, C. T (2010). The Effectiveness of Functional Family Therapy for Youth with Behavioral Problems in a Community Practice Setting. Journal of Family Psychology, 24(3), pp339-348.

Stephenson, M. (2007). Young people and offending: Education, youth justice and social inclusion. Cullompton: Willan.

Stuart, R. B. (1968). Token reinforcement in marital treatment. In R. Rubin \& C. Franks (Eds.), Advances in behavior therapy. New York: Academic Press.

Thurston, M., McLeod, J., \& Thurston, A. (2012). Counselling for sight loss: A hermeneutic single case efficacy design study. Counselling Psychology Review, 27, pp56-70.

Winter, W.D., \& Ferreira, A.J. (1969). Talking time as an index of intrafamilial similarity in normal and abnormal families. Journal of Abnormal Psychology, 74, pp574-575.

Youth Justice Board for England and Wales (2010). Exploring the needs of young Black and Minority Ethnic offenders and the provision of targeted interventions. Available from www.justice.gov.uk/downloads/youth-justice/yjb-toolkits/disproportionality/Exploring-needsyoung-bme-offenders.pdf 